\title{
Comparison of intelligence, weight and height in children after general anesthesia with and without perioperative desaturation in non-cardiac surgery: a historical and concurrent follow-up study
}

Maliwan Oofuvong ${ }^{1 *}$, Alan Frederick Geater², Virasakdi Chongsuvivatwong ${ }^{2}$, Thavat Chanchayanon', Juthamas Worachotekamjorn³, Bussarin Sriyanaluk', Boonthida Saefung ${ }^{1}$ and Kanjana Nuanjun ${ }^{1}$

\begin{abstract}
Purpose: To determine whether perioperative desaturation (PD) in preschool children undergoing non-cardiac surgery is associated with subsequent impairment of intelligence or subsequent change in age-specific weight and height percentile.

Method: A historical-concurrent follow-up study was conducted in children aged $\leq 60$ months who underwent general anesthesia (GA) for non-cardiac surgery between January 2008 and December 2011 at Songklanagarind Hospital. Children who developed PD (PD group) and children who did not develop perioperative respiratory events (no-PRE group) were matched on sex, age, year of having index GA, type of surgery and choice of anesthesia. The children's age-specific weight and height percentile and intelligence quotient (IQ) scores by Standford Binet-LM or Wechsler Intelligence Scale for Children, 3rd edition 12-60 months after GA were compared using Student's t- test and Wilcoxon's rank sum test. Multivariate linear regression models for standardized IQ and multivariate mixed effects linear regression models for the change of age-specific weight and height percentile from the time of index GA to the time of IQ test were performed to identify independent predictors. The coefficients and $95 \%$ confidence intervals (Cl) were displayed and considered significant if the $\mathrm{F}$ test $\mathrm{p}$-values were $<0.05$.

Results: Of 103 subjects in each group (PD vs no-PRE), there were no statistically significant differences in IQ (94.7 vs $98.3, p=0.13$ ), standardized IQ ( -0.1 vs $0.1, p=0.14$ ) or age-specific weight percentile (38th vs 63 th, $p=0.06$ ). However, age-specific height percentile in the PD group at the time of IQ test was significantly lower (38th vs 50 th, $p=0.02$ ). In the multivariate analysis, PD was not a significant predictor for standardized IQ (coefficient: $-0.06,95 \% \mathrm{Cl}:-0.3,0.19$, $p=0.57$ ), change in age-specific weight percentile (coefficient: $4.66,95 \% \mathrm{Cl}:-2.63,11.95, p=0.21$ ) or change in age-specific height percentile (coefficient: $-1.65,95 \% \mathrm{Cl}:-9.74,6.44, \mathrm{p}=0.69)$ from the time of index $\mathrm{GA}$ to the time of IQ test after adjusting for family and anesthesia characteristics.
\end{abstract}

Conclusion: Our study could not demonstrate any serious effect of PD on subsequent intelligence or on the change in age-specific weight and height percentile of children after non-cardiac surgery.

Keywords: Perioperative desaturation; Weight; Height; Intelligence; Pediatric anesthesia; Non-cardiac surgery

\footnotetext{
* Correspondence: oomaliwa@gmail.com

1 Department of Anesthesiology, Faculty of Medicine, Prince of Songkla

University, Songkhla 90112, Thailand

Full list of author information is available at the end of the article
} 


\section{Introduction}

Chronic hypoxia such as occurs in children having congenital cyanotic heart disease or sleep-disordered breathing has been reported to have an impact on long-term neurodevelopment (Hovels-Gurich et al. 2008; Ballweg et al. 2007; Hovels-Gurich et al. 2006; Sananes et al. 2012; Wise-Faberowski and Loepke 2011; Tabbutt et al. 2012; Hill et al. 2006). An intermittent hypoxic episode, especially in preterm infants, is also associated with longer-term cardiorespiratory instability, poor neurodevelopmental outcome and impaired growth (Martin et al. 2011). Perioperative desaturation (PD) is a serious perioperative respiratory event (PRE) as it could lead to cardiac arrest and hypoxic ischemic brain injury. The mechanism of PD occurring in infants with normoxia is similar to the hyperoxic state from resuscitation of acutely asphyxiated infants by using 100\% oxygen, which can generate excessive neurotoxic compounds and increase oxidative stress markers (Wise-Faberowski and Loepke 2011). Moreover, a few studies have reported poor neurodevelopmental outcome following exposure to certain anesthetic agents in combination with low flow cardiopulmonary bypass for complex cardiac surgery in neonates (Sananes et al. 2012; Guerra et al. 2011).

Long-term sequelae regarding intelligence outcome in preschool level and mentally intact children having noncardiac surgery who were exposed to general anesthesia (GA) and developed PD has never been investigated. Thus, PD occurring at a young age regardless of severity combined with GA might possibly have a long-term impact on weight, height and intelligence in preschool and school children. Understanding the long-term consequence may assist the clinician to advise the parents to plan for an affected child's education process. Therefore, the objectives of this study were to compare subsequent intelligence and change in age-specific weight and height percentile of children undergoing GA at age $\leq 60$ months who developed PD and those who had no PRE when having non-cardiac surgery at a tertiary care hospital in southern Thailand.

\section{Materials and methods}

A joint historical-concurrent follow-up study was conducted at Songklanagarind Hospital, an 853-bed tertiary care hospital in southern Thailand, after approval from the Ethics Committee, Prince of Songkla University, on November 15th, 2012 (ClinicalTrials.gov: NCT01965093). Children aged $\leq 60$ months undergoing GA between 2008 and 2011 who developed intraoperative or post-anesthetic care unit (PACU) desaturation (PD group) were compared with others who did not develop any PRE (no-PRE group) in respect of subsequent intelligence and subsequent change in age-specific weight and height percentile.
Children's weight and height parameters and intelligence 12-60 months after exposure to GA were assessed between 2012 and 2013. Written informed consent was obtained from all parents who allowed their children to participate in the study.

\section{Participants}

The anesthetic database and the anesthetic record of children aged $\leq 60$ months undergoing GA between January 2008 and December 2011 were reviewed. Patients were excluded if they were classified as American Society of Anesthesiologists (ASA) classification 4 or 5, had a preoperative oxygen saturation at room air $<95 \%$, were already endotracheally intubated and/or mechanically ventilated prior to surgery, had congenital cyanotic heart disease or cardiac surgery, had neurosurgery, had preoperative delayed development, or had perinatal hypoxia or fetal growth retardation.

\section{The main exposure (PD and no-PRE)}

In our hospital, the anesthetic record is recorded under anesthesia surveillance using continuous pulse oximetry and capnograph monitoring incorporated with the patient's vital signs every 5 minutes. Time of PRE (desaturation, laryngospasm, bronchospasm, upper airway obstruction, reintubation and others) occurring as well as the lowest oxygen saturation by pulse oximetry $\left(\mathrm{SpO}_{2}\right)$ intraoperatively or at PACU are recorded immediately in the vital sign's table and details of PRE are described in the events section. A specific code for each type of PRE is recorded in the anesthetic database. PD was defined as a condition with oxygen saturation $<95 \%$ for more than 10 seconds (Xue et al. 1996) as recorded in the anesthetic database and the anesthetic record. Children with PD were identified from the anesthetic database and confirmed by review of the anesthetic record by the primary investigator $(\mathrm{MO})$.

No-PRE children were defined as those who did not develop any respiratory event intraoperatively or at the PACU period. There was a total of 4639 no-PRE children in the study period. No-PRE children who matched each PD child on sex, age at index GA (within \pm 6 months-range for age $<12$ months, within \pm 12 monthsrange for age $\geq 12$ months), year of having index GA, type of surgery and choice of GA were listed. The variables that did not exist in the hospital database such as maternal education, socioeconomic status, or training by parents, could not be matched. After applying exclusion criteria, only 3 to 4 children were eligible to be included in the noPRE matched set for each PD child, and from these one no-PRE child was selected using simple random sampling. If type of surgery could not be matched exactly with a child from the matching list, another type of surgery using the same choice of GA was used for matching. 
The parents of children in both groups were contacted by the primary investigator (MO) by phone call and/or invitation postcard. If a parent of the PD child declined or could not be reached, the whole matched set was dismissed. If a selected no-PRE child was not available while the PD child was, a second no-PRE child was randomly chosen from the list.

\section{Outcome of interest}

The study subjects of both groups were called back to the study hospital to be assessed on intelligence, weight and height. The timing of IQ tests was arranged so that the age of the matched pair at the time of IQ test differed by no more than 12 months. The duration from the GA to this follow-up assessment (at the time of IQ test) varied almost uniformly between 1 and 5 years. Evaluations were done in each member of a matched pair within a 3-month interval.

Intelligence quotient (IQ), which was the main outcome, was evaluated. Two intelligence tests were employed, namely the Standford Binet form L-M (Becker 2003) and The Wechsler Intelligence Scale for Children, 3rd edition (Watkins 1996; Freberg et al. 2008). The former was used as the main intelligence outcome in our study. It measures cognitive ability regarding verbal reasoning, quantitative reasoning, abstract and visual reasoning and short-term memory skills with a wide range of IQ scores varying from 20 to 140 . The suitable age for using this test is between 2 to 7 years. The Wechsler Intelligence Scale for Children, 3rd edition test was used as a supplemental test for children who reached the ceiling age of 7 years on the Standford Binet form L-M test. It consists of verbal and performance subtests (nonverbal subtest) with a range of IQ scores varying from 70 to 130 . A pediatric psychometrist (TD) established rapport with each child and performed the IQ test in all children. Children aged between 6 to 8 years were screened for the appropriate test using the last page of the Standford Binet form L-M test and then either continued with the Standford Binet form L-M test or switched to the Wechsler Intelligence Scale for Children, 3rd edition, to fit their mental age. Age-normalized IQ was computed using the table in the manual to correlate the mental age from total raw scores with actual age. As these two tests contain different items and use different methods of calculation, the normalized IQ score, standardized within IQ test were calculated and used as the final intelligence variable. Therefore, the final intelligence score had mean of 0 and standard deviation (SD) of 1 .

Body weight and height of children wearing light clothing with empty pockets were measured using a Detecto scale and stadiometer. The weight and height of each child were compared with the weight-to-height data from the Nutrition Division, Ministry of Public
Health, to obtain age-specific weight and height percentiles. Then, weight, age-specific weight percentile (ASWP), height and age-specific height percentile (ASHP) were compared between the two groups both at the time of index GA and at the time of IQ test. Age (months) at first talk (first meaningful word) and at first walk (walk without assistance) were also recorded.

\section{Potential confounding variables}

Child- and family-related characteristics were obtained during interview by $\mathrm{MO}$ while anesthesia-related variables were obtained from the anesthesia database by BS, $\mathrm{BS}$ and $\mathrm{KN}$ and review of the anesthetic recorded by MO. Child- and family-related characteristics (12 variables) included history of prematurity, history of parental smoking, religion, mother's age at delivery, mother's occupation, father's occupation, monthly quintile of family income (baht), mother's education, father's education, children's education, training by parents (none, partial or regular) (Additional file 1) and child's capability (needing full help, partial help or no help) (Additional file 2) (Table 1). Variables to represent training by parents and child's capability were constructed by the investigator team to be included as potential confounders. They were used for the research purposes only.

Eleven anesthesia-related variables were ASA classification, number of repeated GA, type of surgery, choice of GA, technique of GA, induction agent, intubating agent, inhalation agent, gas mixed with oxygen, narcotic and duration of GA (Table 2).

\section{Statistical analysis}

Descriptive statistics of various variables, including frequency (\%), mean and SD, median and interquartile ranges (IQR) in the $\mathrm{PD}$ and the no-PRE groups were computed. Student's t-test or non-parametric rank sum test as appropriate for continuous variables and Chisquare test or Fisher's exact test as appropriate for categorical variables were employed to check for significant difference of background characteristics of the two groups and their differences in parameters of weight, height and IQ. As the two groups were not perfectly balanced, final comparison on intelligence, age-specific weight and height percentile were adjusted for potential confounders using multivariate analysis.

To examine the relationship between PD and subsequent normalized IQ score, standardized within IQ test, a multivariate linear regression model was developed. All variables with $\mathrm{p} \leq 0.2$ in univariate analysis or otherwise of interest were included in the initial model, and the model refined by sequential backward elimination of non-significant variables (likelihood ratio test). Some significant variables between the PD and no-PRE groups were forced to remain in the final model of multivariate 
Table 1 Comparison of demographic data and family-related variables between the two groups

\begin{tabular}{llll}
\hline Variables & PD $(n=103)$ & $\begin{array}{l}\text { No-PRE } \\
(n=103)\end{array}$ & p-value \\
\hline
\end{tabular}

Demographic data

$\operatorname{Sex}(\mathrm{M}: \mathrm{F})$

Age at index

$\mathrm{GA}$ (months)

Weight at index

$\mathrm{GA}(\mathrm{kg})^{\mathrm{a},+}$

ASWP at index $G A^{a,+}$

Height at index

$\mathrm{GA}(\mathrm{cm})^{\mathrm{a},+}$

ASHP at index $\mathrm{GA}^{\mathrm{a},+}$

Family-related variables

Parental smoking ${ }^{\mathrm{b}, \neq}$

No
Yes
Religion ${ }^{\text {b,f }}$
Buddhist
Muslim

Mother's age at
delivery (yr) ${ }^{c, \$}$
Mother's occupation ${ }^{\mathrm{b}, \neq}$

None
Company employee
Farmer

Government officer

Self-employee

Father's occupation $^{\mathrm{d}, \mathrm{f}}$

None

Farmer

Government officer

Self-employee

Income quintiles $(b a h t)^{b, \neq}$

$<10,000$

$$
42(40.8)
$$

$43(41.7)$

61 (59.2)

$60(58.3)$

81 (78.6)

$22(21.4)$

$29.7(6.2)$

13 (12.6)

13 (12.6)

$33(32.0)$

27 (26.2)

$27(26.2)$

20 (19.4)

$8(7.8)$

$22(21.4)$

$21(20.4)$

$22(21.4)$

$1(1.0)$

2 (1.9)

33 (32.0)

$32(31.1)$

$24(23.3)$

$24(23.3)$

16 (15.5)

$21(20.4)$

17 (16.5)

$23(22.3)$

27 (26.2)

$10,001-17,800$

$17,801-30,000$

$30,001-40,000$

40,001-500,000

Mother's education, ${ }^{\mathrm{b}, \mathrm{f}}$

Primary school

Secondary school

Tertiary education

Father's education ${ }^{\mathrm{b}, \text { f }}$

Primary school

Secondary school
$23(22.3)$

$33(32.0)$

$7(6.8)$

$21(20.4)$

21 (20.4)

35 (34.0)

47 (45.6)
0.31
Table 1 Comparison of demographic data and family-related variables between the two groups (Continued)

\begin{tabular}{|c|c|c|c|}
\hline Tertiary education & $45(43.7)$ & $47(45.6)$ & \\
\hline \multicolumn{4}{|l|}{ Child-related variables } \\
\hline Prematurity ${ }^{\mathrm{b}, \neq}$ & & & 0.86 \\
\hline No & $81(78.6)$ & $83(80.6)$ & \\
\hline Yes & $22(22.4)$ & $20(19.4)$ & \\
\hline Children's education ${ }^{\mathrm{b}, \mathrm{t}}$ & & & 0.17 \\
\hline Home & $18(17.5)$ & $11(10.7)$ & \\
\hline Nursery & $7(6.8)$ & $12(11.7)$ & \\
\hline Pre-kindergarden & $10(9.7)$ & $15(14.6)$ & \\
\hline Kindergarden & $60(58.3)$ & $51(49.5)$ & \\
\hline Primary school & $8(7.8)$ & $14(13.6)$ & \\
\hline Training by parents & & & 0.41 \\
\hline None & $4(3.9)$ & $1(1.0)$ & \\
\hline Partial & $67(65.0)$ & $66(64.0)$ & \\
\hline Regular & $32(31.1)$ & $36(35.0)$ & \\
\hline Children's capability ${ }^{\mathrm{d}, \neq}$ & & & 0.77 \\
\hline Full help & $1(1.0)$ & $0(0)$ & \\
\hline Partial help & $36(35.0)$ & $34(33.0)$ & \\
\hline No help & $66(64.0)$ & $69(67.0)$ & \\
\hline First talk (months) & $18(15-24)$ & $18(15-21)$ & 0.97 \\
\hline First walk (months) ${ }^{a,+}$ & $14(12-18)$ & $14(12-18)$ & 0.38 \\
\hline
\end{tabular}

linear regression even though they were non-significant variables in the final model. After obtaining the final model, PD was replaced with a variable indicating severity of PD (no-PRE, mild to moderate and severe PD).

To model the relationship between $\mathrm{PD}$ and agespecific weight and height percentile, data were reshaped into long format (412 records) to expand the agespecific weight and height percentile into 2 times: at the time of index GA and at the time of IQ test and these percentiles were considered as repeated measures to be fitted into the mixed effects model. Final comparison of change in weight and height between PD and no-PRE group was adjusted for factors significantly associated with the age-specific weight and height percentile at the 2 times using multivariate mixed effects linear regression models with random intercept by fitting an interaction term between time and main exposure (time $\times$ PD). Some significant variables between the PD and no-PRE groups were forced to remain in the final model of multivariate mixed effects linear regression even though they were non-significant variables in the final model. 
Table 2 Comparison of anesthesia-related variables between the two groups

\begin{tabular}{|c|c|c|c|}
\hline Variables & $P D(n=103)$ & $\begin{array}{l}\text { No-PRE } \\
(n=103)\end{array}$ & $p$-value \\
\hline Repeated GA (per time) $)^{\mathrm{a},+}$ & $0(0-2)$ & $0(0-1)$ & 0.08 \\
\hline ASA classification ${ }^{\mathrm{b}, \neq}$ & & & 0.32 \\
\hline 1 & $17(16.5)$ & $13(12.6)$ & \\
\hline 2 & $67(64.1)$ & $77(73.8)$ & \\
\hline 3 & $20(19.4)$ & $14(13.6)$ & \\
\hline Type of surgery $^{\ddagger}$ & & & - \\
\hline Abdominal & $36(34.9)$ & $37(35.9)$ & \\
\hline Ear nose throat & $20(19.4)$ & $22(21.4)$ & \\
\hline Eye & $9(8.7)$ & $9(8.7)$ & \\
\hline Thoracic & $8(7.8)$ & $7(6.8)$ & \\
\hline Orthopedic & $18(17.5)$ & $18(17.5)$ & \\
\hline Cardiac catheterization & $4(3.9)$ & $4(3.9)$ & \\
\hline Superficial & $8(7.8)$ & $6(5.8)$ & \\
\hline Choice of $G A^{\ddagger}$ & & & - \\
\hline GA only & $67(65.0)$ & $64(62.1)$ & \\
\hline GA combined RA or PNB & $36(35.0)$ & 39 (37.9) & \\
\hline Technique of $G A^{c, \neq}$ & & & 0.77 \\
\hline Mask & $11(10.7)$ & $9(8.7)$ & \\
\hline Laryngeal mask airway & $26(25.2)$ & $23(22.3)$ & \\
\hline Total intravenous anesthesia & $1(1.0)$ & $1(1.0)$ & \\
\hline ETT with inhalation & $7(6.8)$ & $10(9.7)$ & \\
\hline ETT with balanced & $58(56.3)$ & $60(58.3)$ & \\
\hline Induction agents ${ }^{\mathrm{c}, \neq}$ & & & 0.46 \\
\hline Thiopental & $55(53.4)$ & $55(53.4)$ & \\
\hline Sevoflurane & $38(36.9)$ & $43(41.7)$ & \\
\hline Propofol & $8(7.8)$ & $3(2.9)$ & \\
\hline Ketamine & $2(1.9)$ & $2(1.9)$ & \\
\hline Intubating agents ${ }^{\mathrm{c}, \neq}$ & & & 0.24 \\
\hline Succinylcholine & $20(19.4)$ & $12(11.7)$ & \\
\hline NDMR & $43(41.7)$ & $53(51.5)$ & \\
\hline Sevoflurane & $1(1.0)$ & $4(3.9)$ & \\
\hline Propofol & $1(1.0)$ & $1(1.0)$ & \\
\hline None & $38(36.9)$ & $33(32.0)$ & \\
\hline Inhalation agent ${ }^{\mathrm{c}, \neq}$ & & & 0.30 \\
\hline Sevoflurane & $88(85.4)$ & $96(93.2)$ & \\
\hline Isoflurane & $5(4.9)$ & $3(2.9)$ & \\
\hline Desflurane & $8(7.8)$ & $3(2.9)$ & \\
\hline None & $2(1.9)$ & $1(1.0)$ & \\
\hline Gas mixed with oxygen ${ }^{c, \neq}$ & & & 0.49 \\
\hline Air & $57(55.3)$ & $51(48.5)$ & \\
\hline Nitrous oxide & $44(42.7)$ & $52(50.5)$ & \\
\hline $100 \%$ oxygen & $2(1.9)$ & $1(1.0)$ & \\
\hline Narcotics ${ }^{c, \neq}$ & & & 0.41 \\
\hline
\end{tabular}

Table 2 Comparison of anesthesia-related variables between the two groups (Continued)

\begin{tabular}{llll}
\hline Intravenous fentanyl & $79(76.7)$ & $75(72.8)$ & \\
Intravenous morphine & $2(1.9)$ & $4(3.9)$ & \\
Epidural morphine & $14(13.6)$ & $11(10.7)$ & \\
None & $7(6.8)$ & $13(12.6)$ & \\
$\begin{array}{l}\text { Duration of GA (hours) }{ }^{\mathrm{b}, \neq} \\
<1\end{array}$ & $10(9.7)$ & $21(20.4)$ & \\
$1-3$ & $78(75.7)$ & $75(72.8)$ & \\
$>3$ & $15(14.6)$ & $7(6.8)$ & \\
$\begin{array}{l}\text { Perioperative lowest oxygen } \\
\text { saturation }\end{array}$ & $91(70-93)$ & $99(98-99)$ & $0.001^{*}$
\end{tabular}

${ }^{\mathrm{a}}$ Rank sum test, ${ }^{\mathrm{b}} \mathrm{Chi}$-square test, ${ }^{\mathrm{C}}$ Fisher's exact test, ${ }^{*} \mathrm{p}$-value $<0.05,{ }^{+}$median (IQR), " number (\%), ASA; American Society of Anesthesiologists, ETT; Endotracheal tube intubation, GA; General anesthesia, NDMR; Non depolarizing muscle relaxant, PD; Perioperative desaturation, PNB; Peripheral nerve block, PRE; Perioperative respiratory event, RA; regional anesthesia.

The coefficients and 95\% confidence intervals (CI) were displayed and considered significant if the $\mathrm{F}$ test p-values were $<0.05$.

\section{Sample size calculation}

For a power of $90 \%$ and type I error of 5\%, 85 children per group were required to detect a difference of $\geq 0.5$ SD (i.e., a clinically significant mean difference of IQ score of 6 and SD of 12), based on a study by Sungthong et al. (Sungthong et al. 2004) of southern Thai children's IQ at age $<9$ years. A total of 100 children per group would be required to compensate for $15 \%$ drop out.

\section{Results}

Figure 1 shows a flow diagram of our cohort study. A total of 188 children aged $\leq 60$ months having PD after GA from January 2008 to December 2011 at Songklanagarind Hospital was identified. All of these children had duration of $\mathrm{PD}<60$ seconds. Eighty-five were excluded for the following reasons: 33 had preoperative delayed development, 22 refused to participate, 24 were lost to contact, 3 died after surgery and 3 matched pairs were excluded (2 PD children and 1 no-PRE child were suspected of having pervasive developmental disorders (PDD)). Among the 103 PD children, causes of PD were hypoventilation (32\%), laryngospasm (26\%), bronchospasm (21\%), upper airway obstruction (9\%), accidental extubation (5\%), pulmonary aspiration (3\%), difficult airway (3\%) and pneumothorax (1\%). Forty-one (40\%) and 62 children (60\%) developed severe $\left(\mathrm{SpO}_{2} \leq 85 \%\right)$ and mild to moderate PD $\left(\mathrm{SpO}_{2}\right.$ 86-94\%), respectively. These 103 children in the PD group were matched with 103 children with no-PRE. Following the IQ test, children who were suspected of having PDD or had an IQ score $<70$ were sent to the child developmental clinic. 


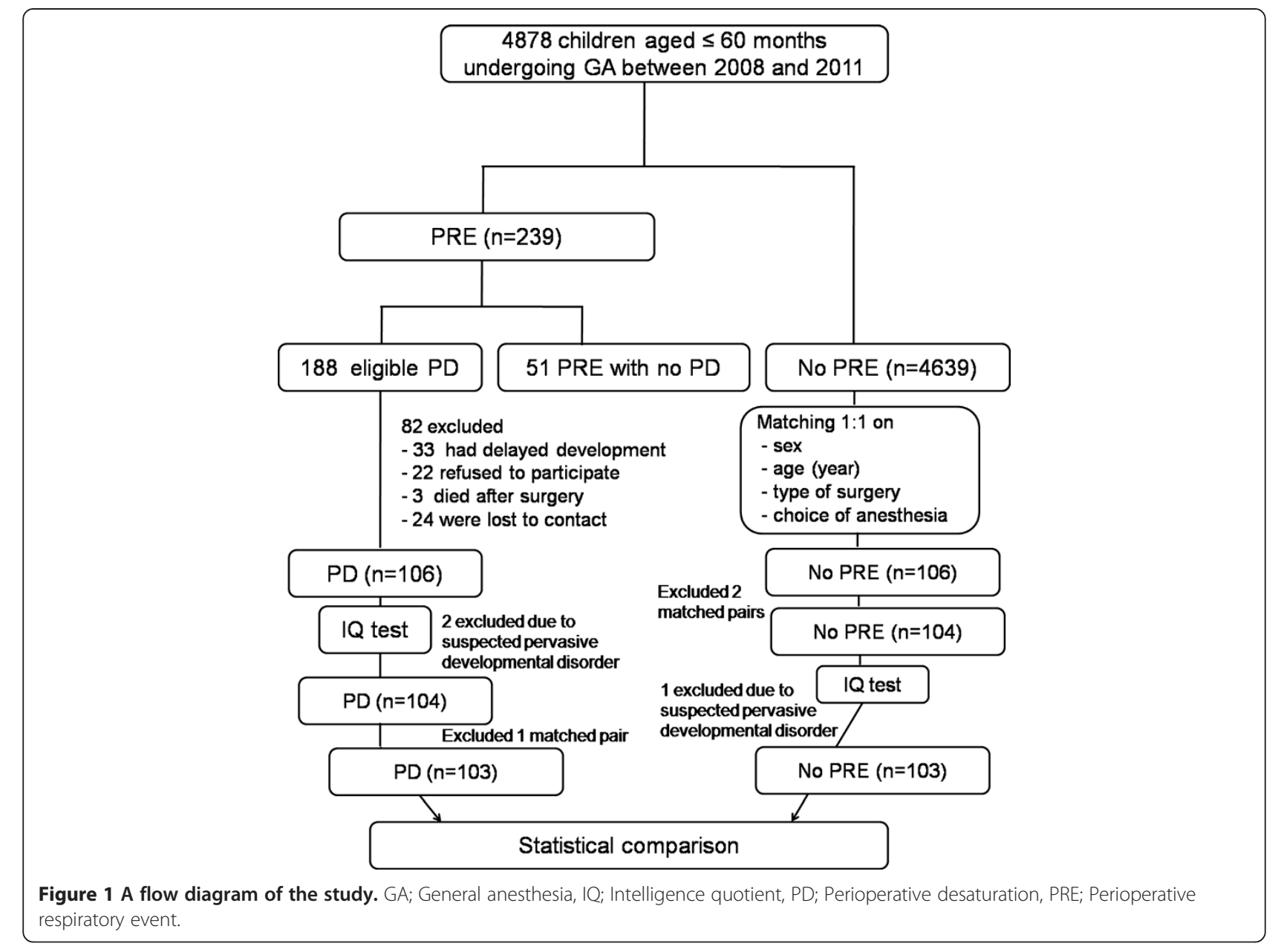

\section{Association between PD and PDD}

Two children from the PD group were suspected of having PDD and therefore excluded. The two no-PRE children from matched pairs of PD group having PDD were not called back at the time of assessment because they would also be excluded. In addition, one child from the no-PRE group was suspected of having PDD and this matched pair was also excluded. However, to explore the possible association between PD and PDD based on 3 possible results, a sensitivity analysis was conducted. Two-by-two tables of the 3 possible results were constructed and the Fisher's exact test was performed to determine the association in each situation. The results showed no association between PD and PDD in any of the 3 situations: no children, 1 child or 2 children having PDD (odds ratio: $2.02,95 \% \mathrm{CI}: 0.18-22.6, \mathrm{p}=1$, odds ratio: $1.0,95 \% \mathrm{CI}$ : $0.14-7.23, \mathrm{p}=1$, odds ratio: $0.66,95 \%$ CI: 0.11-4.03, $\mathrm{p}=1$, respectively).

Table 1 compares children's baseline demographic data and family-related variables between the two groups. Only ASWP at index GA differed significantly between the two groups. The ASWP at index GA in the PD group was significantly lower than that in the no-PRE group (25th vs 38th, $\mathrm{p}=0.007$ ). Table 2 compares anesthesia-related variables between the two groups. There were no significant differences in anesthesiarelated variables between the two groups except duration of GA. Duration of GA in the PD group was significantly longer than that in the no-PRE group (115 vs 85 minutes, $\mathrm{p}=0.001$ ). The median perioperative lowest oxygen saturation was significantly lower in the PD group than in the no-PRE group (91\% vs $99 \%, \mathrm{p}=0.001$ ).

Table 3 shows a comparison of weight, height and intelligence at the time of IQ test between the two groups. None of the outcome variables except those related to weight and height differed significantly between the two groups. The weight $(\mathrm{kg})$, height $(\mathrm{cm})$ and ASHP of children were significantly higher in the no-PRE group than in the PD group at the time of IQ test (18 vs $16.6 \mathrm{~kg}, 107$ vs $104 \mathrm{~cm}, 50$ th vs 38 th, $\mathrm{p}=0.04, \mathrm{p}=0.01$ and $\mathrm{p}=0.02$, respectively). Subgroup analysis in the PD group showed no differences in age-normalized IQ among severe $\left(\mathrm{SpO}_{2} \leq\right.$ $85 \%)$ and mild to moderate $\mathrm{PD}\left(\mathrm{SpO}_{2} 86-94 \%\right)$ compared to no-PRE group (93.6, 95.5 vs 98.3, $\mathrm{p}=0.27$, respectively). 
Table 3 Weight, height and intelligence at the time of IQ test

\begin{tabular}{|c|c|c|c|}
\hline Variables & $P D(n=103)$ & $\begin{array}{l}\text { No-PRE } \\
(n=103)\end{array}$ & p-value \\
\hline$\overline{\text { Age (months) }}{ }^{+}$ & $58(43-72)$ & $58(46.5-74)$ & - \\
\hline Weight $(\mathrm{kg})^{\mathrm{a},+}$ & $16.6(14-19)$ & $18(15-21)$ & $0.04^{*}$ \\
\hline ASWP $P^{a,+}$ & 38th (18th-63th) & 63th (32th-75th) & 0.06 \\
\hline Height $(\mathrm{cm})^{a,+}$ & $104(97-112)$ & $107(101-116)$ & $0.01^{*}$ \\
\hline ASHP $\mathrm{P}^{\mathrm{a},+}$ & 38th (18th-63th) & 50th (25th-75th) & $0.02^{*}$ \\
\hline Mental age (months) ${ }^{a,+}$ & $58(40.5-67)$ & $60(44.5-74)$ & 0.08 \\
\hline Age-normalized $I Q^{\mathrm{b}, \neq}$ & $94.7(16.0)$ & $98.3(17.5)$ & 0.13 \\
\hline $\begin{array}{l}\text { Normalized IQ score, } \\
\text { standardized within } \\
\text { IQ test }{ }^{\mathrm{b}, \neq}\end{array}$ & $-0.10(0.9)$ & $0.10(1.0)$ & 0.14 \\
\hline Intelligence test ${ }^{c, \S}$ & & & 0.25 \\
\hline SB-LM & $90(87.4)$ & $83(80.6)$ & \\
\hline WISC III & $13(12.6)$ & $20(19.4)$ & \\
\hline \multicolumn{4}{|c|}{ Age-normalized IQ by each test } \\
\hline IQ score by SB-LM ${ }^{\mathrm{b}, \neq}$ & $94.5(16.5)$ & $98.1(18.7)$ & 0.18 \\
\hline IQ score by WISC III ${ }^{\mathrm{b}, \neq}$ & $96.8(12.5)$ & $99.2(11.7)$ & 0.57 \\
\hline $\begin{array}{l}\text { Age-normalized IQ } \\
\text { by lowest }\end{array}$ & & & 0.27 \\
\hline \multicolumn{4}{|l|}{$\mathrm{SpO}_{2}^{\mathrm{d}, \neq}$} \\
\hline $\mathrm{SpO}_{2} \geq 95$ & & $98.3(17.5)$ & \\
\hline $\mathrm{SpO}_{2} 86-94$ & $95.5(16.1)$ & & \\
\hline $\mathrm{SpO}_{2} \leq 85$ & $93.6(16.1)$ & & \\
\hline
\end{tabular}

${ }^{\mathrm{a}}$ Rank sum test, ${ }^{\mathrm{b}}$ Student's t- test, ${ }^{\mathrm{c}}$ Chi-square test, ${ }^{\mathrm{d}} \mathrm{ANOVA}$ test, ${ }^{*} \mathrm{p}$-value $<0.05$, ${ }^{+}$median (IQR), ${ }^{\ddagger}$ mean (SD), ${ }^{\S}$ number (\%), ASWP; Age-specific weight percentile, ASHP; Age-specific height percentile, IQ; Intelligence quotient, PD; Perioperative desaturation, PRE; Perioperative respiratory event, SB-LM; Standford Binet form L-M, $\mathrm{SpO}_{2}$; Oxygen saturation by pulse oximetry, WISC III; Wechsler Intelligence Scale for Children, 3rd edition.

Univariate and multivariate analysis of the normalized IQ score, standardized within IQ test related to PD

All 13 child- and family-related variables including ASWP at the time of index GA and 12 anesthesiarelated variables including occurrence of PD were examined in the univariate analysis of normalized IQ score, standardized within IQ test. The following 8 variables having $\mathrm{p} \leq 0.2$ in the univariate analysis were included in the initial multivariate model but became non-significantly related to normalized IQ score, standardized within IQ test in the multivariate analysis: religion, mother's age at delivery, mother's occupation, father's occupation, income quintiles, child's education, children's capability and gas mixed with oxygen. Table 4 shows results of the multivariate linear regression analysis predicting normalized IQ score, standardized within IQ test, from exposure to PD and other confounding variables. After adjusting for ASWP at the time of index GA, mother's education, father's education, training by parents, repeated times of GA and duration of GA, PD was not an independent risk
Table 4 Multivariate linear regression predictingthe normalized IQ score, standardized within IQ test from PD exposure $(n=206)$

\begin{tabular}{|c|c|c|}
\hline \multirow[t]{2}{*}{ Variables } & \multicolumn{2}{|c|}{ Multivariate } \\
\hline & $\begin{array}{c}\text { Coefficient } \\
(95 \% \mathrm{Cl})\end{array}$ & p-value \\
\hline $\begin{array}{l}\text { Age-specific weight percentile } \\
\text { at index GA }\end{array}$ & $0.003(-0.001,0.007)$ & 0.16 \\
\hline $\begin{array}{l}\text { Mother's education (ref = Tertiary } \\
\text { education) }\end{array}$ & & $<0.001$ \\
\hline Secondary school & $-0.34(-0.67,-0.01)$ & \\
\hline Primary school & $-0.38(-0.83,0.06)$ & \\
\hline $\begin{array}{l}\text { Father's education (ref }=\text { Tertiary } \\
\text { education) }\end{array}$ & & 0.007 \\
\hline Secondary school & $-0.43(-0.75,-0.11)$ & \\
\hline Primary school & $-0.35(-0.78,0.07)$ & \\
\hline Training by parents (ref = Regular) & & 0.007 \\
\hline Partial & $-0.41(-0.69,-0.13)$ & \\
\hline None & $-1.0(-1.84,-0.15)$ & \\
\hline Repeated GA (per time) & $-0.04(-0.08,-0.01)$ & 0.01 \\
\hline Duration of GA (hours) (ref $=<1$ ) & & 0.37 \\
\hline $1-3$ & $0.07(-0.28,0.41)$ & \\
\hline$>3$ & $-0.21(-0.7,0.27)$ & \\
\hline$P D(r e f=N o-P R E)$ & & 0.57 \\
\hline Yes & $-0.06(-0.3,0.19)$ & \\
\hline Severity of PD (ref = No-PRE) & & 0.56 \\
\hline Mild to moderate PD $\left(\mathrm{SpO}_{2}\right.$ 86-94) & $0.02(-0.27,0.31)$ & \\
\hline Severe PD $\left(\mathrm{SpO}_{2} \leq 85\right)$ & $-0.16(-0.49,0.16)$ & \\
\hline
\end{tabular}

p-value by $\mathrm{F}$ test statistic, GA; General anesthesia, IQ; Intellligence quotient, $\mathrm{PD}$; Perioperative desaturation, PRE; Perioperative respiratory event, $\mathrm{SpO}_{2}$; Oxygen saturation by pulse oximetry.

factor for normalized IQ score, standardized within IQ test (coefficient: $-0.06,95 \% \mathrm{CI}:-0.3,0.19, \mathrm{p}=0.57$ ). After replacing PD with severity of PD, there was no evidence that severity of PD was an independent risk factor for normalized IQ score, standardized within IQ test $(\mathrm{p}=0.56)$ in our study.

Univariate and multivariate analysis for change in age-specific weight and height percentile related to PD

All 12 child- and family-related variables and 12 anesthesia-related variables including occurrence of PD were examined in the univariate analysis of the change in age-specific weight and height percentile. The following 7 variables having $\mathrm{p} \leq 0.2$ in the univariate analysis were included in the initial multivariate model but became non-significantly related to change in ASWP in the multivariate analysis: history of prematurity, religion, mother's education, father's education, ASA classification, type of surgery and technique of GA. The following 3 variables having $\mathrm{p} \leq 0.2$ in the univariate analysis were included and 
became non-significantly related to change in ASHP in the multivariate analysis: children's capability, type of surgery and duration of GA. Table 5 shows the results of the multivariate mixed effects linear regression models predicting the change in age-specific weight and height percentile from the time of index GA to the time of IQ test after exposure to $\mathrm{PD}$ and other confounding variables. After adjusting for income quintile, number of times of repeated GA and duration of GA, PD was not an independent risk factor for change in ASWP (coefficient: 4.66, 95\% CI: $-2.63,11.95, \mathrm{p}=0.21$ ). Similarly, after adjusting for income quintile, number of times of repeated GA, history of prematurity, choice of GA , technique of GA and duration of GA, PD was not an independent risk factor for change in ASHP (coefficient: $-1.65,95 \% \mathrm{CI}:-9.74,6.44, \mathrm{p}=0.69$ ). However, PD was significantly associated with a lower
ASWP at the time of index GA (coefficient: -12.6, 95\% CI: $-21.3,-3.76, \mathrm{p}=0.005$ ). Figure 2 shows the change in age-specific weight and height percentile from the time of index GA to the time of IQ test in each group.

\section{Discussion}

Our study could not demonstrate any serious effect of transient perioperative desaturation on subsequent intelligence or on the change in age-specific weight and height percentile of children after non-cardiac surgery. According to the National Thai Survey in 2007, the average IQ score of southern Thai children (96.9) using the Standard Progressive Matrices (a nonverbal test) of IQ measurement (Raven 1938) was slightly lower than the IQ score in the no-PRE group (98.3) and higher than the IQ score in the PD group (94.7).

Table 5 Multivariate mixed effects linear regression predicting the change of age-specific weight and height percentile $(n=412)$

\begin{tabular}{|c|c|c|c|c|}
\hline \multirow[t]{2}{*}{ Variables } & \multicolumn{2}{|c|}{ ASWP } & \multicolumn{2}{|c|}{ ASHP } \\
\hline & Coefficient $(95 \% \mathrm{Cl})$ & $\overline{p \text {-value }}$ & Coefficient $(95 \% \mathrm{Cl})$ & p-value \\
\hline Prematurity $($ ref $=$ No) & & & & 0.03 \\
\hline Yes & - & & $-10.46(-19.65,-1.28)$ & \\
\hline Income quintiles (baht) & & 0.008 & & 0.01 \\
\hline \multicolumn{5}{|l|}{$($ ref $=30,001-40,000)$} \\
\hline $40,001-500,000$ & $-9.66(-24.1,4.75)$ & & $-9.80(-22.8,3.82)$ & \\
\hline $17,801-30,000$ & $-1.68(-15.2,11.8)$ & & $-8.98(-21.5,3.55)$ & \\
\hline $10,001-17,800$ & $-7.91(-23.22,7.39)$ & & $-15.1(-29.1,-1.09)$ & \\
\hline$\leq 10,000$ & $-20.1(-34.0,-6.15)$ & & $-21.2(-33.9,-8.40)$ & \\
\hline Repeated GA (per time) & $-1.28(-2.36,-0.20)$ & 0.02 & $-1.17(-2.20,-0.14)$ & 0.03 \\
\hline Choice of GA & & & & 0.02 \\
\hline (ref = GA only) & - & & & \\
\hline GA combined RA/ PNB & & & $-9.67(-17.7,-1.63)$ & \\
\hline Technique of GA & & & & 0.02 \\
\hline \multicolumn{5}{|l|}{$($ ref $=L M A)$} \\
\hline Facemask & - & & $-8.24(-23.7,7.2)$ & \\
\hline ETT & & & $-12.7(-21.8,-3.59)$ & \\
\hline Duration of GA (ref $=<1)$ & & 0.26 & & 0.74 \\
\hline $1-3$ & $9.09(-1.98,20.2)$ & & $3.69(-8.42,15.8)$ & \\
\hline$>3$ & $5.81(-10.1,21.7)$ & & $6.54(-10.05,23.1)$ & \\
\hline PD (ref = No-PRE) & & 0.005 & & 0.11 \\
\hline \multicolumn{5}{|l|}{ at time of index GA } \\
\hline Yes & $-12.6(-21.3,-3.76)$ & & $-6.84(-15.2,1.54)$ & \\
\hline Time (ref = At index GA) & & 0.04 & & 0.03 \\
\hline \multicolumn{5}{|l|}{ in no-PRE group } \\
\hline At IQ test & $5.41(0.25,10.56)$ & & $6.40(0.68,12.1)$ & \\
\hline Interaction: time $\times$ PD & $4.66(-2.63,11.95)$ & 0.21 & $-1.65(-9.74,6.44)$ & 0.69 \\
\hline
\end{tabular}






Figure 2 The change of weight and height percentile from index GA to the IQ test in each group. GA; General anesthesia, IQ; Intelligence quotient, PD; Perioperative desaturation, PRE; Perioperative respiratory event.

\section{PD and other confounders related to intelligence}

In the current study, there was no significant impairment of intelligence assessed more than one year after developing transient hypoxic events (less than 60 seconds) during intraoperative or PACU period in non-chronic hypoxic children. Two previous studies of congenital cyanotic cardiac surgery have supported our finding in terms of no differences in neurodevelopment outcome of chronic hypoxia or cardiac arrest children when compared with healthy children or children with no cardiac arrest, respectively (Hövels-Gürich et al. 2001; Hansen et al. 2011). However, the reasons why PD itself was not associated with intelligence outcome in our study can be explained as follows. Firstly, desaturation in our study would have been for only a short period (less than 60 seconds) since our anesthesiologists attempted to reduce and correct PD immediately. Severe and long duration of PD may induce hypoxic ischemic brain injury and result in cell apoptosis and necrotic cell death (Baburamani et al. 2012). The lack of differences in IQ score in mild to moderate $\left(\mathrm{SpO}_{2}\right.$ 86-94\%) and severe desaturation $\left(\mathrm{SpO}_{2} \leq 85 \%\right)$ compared to no-PRE $(\mathrm{p}=0.27)$ in our study could also be due to the brief duration of PD. Secondly, intelligence in children is multifactorial. GA itself that includes anesthetic agents involving $\gamma$-aminobutyric acid receptors eg; inhalation agents, midazolam, and N-methyl$\mathrm{D}$-aspartate receptor antagonists such as ketamine, may affect neurodevelopment outcomes by disturbing mitochondrial morphogenesis and resulting in neuroapoptosis in the developing rat brain (Boscolo et al. 2013) although evidence in human babies is still uncertain (Sananes et al. 2012; Sun 2010). Our study could not identify any significant association between various types of anesthetic agents and IQ score. However, our finding that the number of repeated episodes of GA was not significantly different between the two groups $(\mathrm{p}=0.08)$ but was a significant factor related to lower IQ $(p=0.01)$ suggests that GA itself rather than PD may influence neurodevelopmental outcomes in preschool children undergoing non-cardiac surgery. Our result was comparable to a study by Kayaalp et al. (Kayaalp et al. 2006) which found that repeated GA may influence psychological health in children.

Other factors reported to have an impact on intelligence outcome are family characteristics. Our study showed that low mother's education $(\mathrm{p}<0.001)$, low father's education $(\mathrm{p}=0.007)$ and no regular training by parents $(\mathrm{p}=0.007)$ were significant predictors for low IQ. Our findings were consistent with a study by Vanderveen et al. (Vanderveen et al. 2009) showing that high parent education and early intervention in premature infants such as infant stimulation improved neurodevelopment outcomes in children aged less than 36 months.

\section{PD and association with PDD}

In the current study, there was no evidence that PD was associated with $\operatorname{PDD}(\mathrm{p}=1)$. A meta-analysis showed some 
perinatal and neonatal factors such as fetal distress, birth injury or trauma, multiple birth, maternal hemorrhage, low birth weight or low 5-minute apgar score, were associated with autism, whereas delivery by anesthesia was not a risk factor for autism (Gardener et al. 2011). However, no previous studies have shown an association between receiving GA or developing PD and having PDD in preschool children.

\section{PD and other confounders related to change in age-specific weight and height percentile}

In the current study, desaturation occurring intraoperatively or at PACU in preschool children was not significantly associated with subsequent change in age-specific weight or height percentile examined between 2 times: at the time of index GA and at the time of IQ test. Multivariate mixed effects regression was performed to estimate the change in age-specific weight and height percentile from the values at the time of index GA since we found a significant association between PD and lower ASWP at the time of index GA $(p=0.007)$. Our study showed that the number of repeated episodes of GA was significantly associated not only with lower IQ but also with a lower age-specific weight and height percentile $(\mathrm{p}=0.02$ and $\mathrm{p}=0.03$, respectively). Moreover, anesthesiarelated factors associated with lower age-specific height percentile were GA combined with regional anesthesia and technique of GA with ETT. According to our cohort study, it may be more likely that low age-specific weight or height percentile from poor nutrition was a determinant for repeated surgery, repeated GA and using a particular choice and technique of GA. However, to date, this has not been shown in other relevant studies.

Other confounders related to lower age-specific weight and/or height percentile from the time of index GA to the time of IQ test found in our study were not surprising: low monthly family income $(\leq 10,000$ baht or US\$ 333.33) $(\mathrm{p}=0.008$ for ASWP and $\mathrm{p}=0.01$ for ASHP $)$ and prematurity $(\mathrm{p}=0.03)$. Moilanen et al. (Moilanen et al. 2009) reported that family poverty was associated with slower growth in early childhood. The association between low income and lower age-specific weight and height percentile in our study could possibly be explained by poor nutritional status, which is an important factor for intelligence and growth (Sandjaja et al. 2013) but nutritional status was not assessed in our study. Bocca-Tjeertes et al. (Bocca-Tjeertes et al. 2011) also supported our finding that growth restraint was associated with preterm-born children compared to term-born children.

\section{Strengths and limitations}

The strength of the current study was that children in the two groups were matched on sex, age, year of having index GA, type of surgery and choice of anesthesia to reduce the level of confounding between the PD and noPRE groups. In addition, this study employed multiple linear regression analysis which takes into account adjustment for other confounding factors. Moreover, the intelligence outcome assessment was carried out by only one experienced pediatric psychometrist, who was not aware of the child's exposure status (PD or no-PRE) at the time of the assessment.

There were some limitations of the study. Firstly, assessment of the outcomes was done only once. We did not assess intelligence in presumed mentally healthy children before children received GA. We could not know if any children had mildly delayed milestones at the index GA, which may have resulted in a lower IQ score than normal milestone children. Secondly, the newer version of the Standford Binet (the Standford Binet 5th edition) test was not performed in our study because Songklanagarind Hospital provides only the performance subtest (nonverbal IQ subtest) for the Standford Binet 5th edition while the verbal subtest of SB5 has not yet been standardized in Thai language. We believe the Standford Binet form L-M test would provide more benefit to school children and parents in terms of neurodevelopment than the performance subtest of the Standford Binet 5th edition. Lastly, because our study was based on an effect size of $0.5(6 / 12)$, the sample size was too small to detect a smaller difference in IQ scores between the two groups. Furthermore, the variability in IQ (in each group) was actually greater than SD of 12 (SD of 16 and 17.5 in the PD and no-PRE group, respectively).

Based on the study design and method of analysis, the validity of our findings is plausible. Because the study was done in a referral hospital, the generalizability to southern Thai children population is probably satisfactory.

\section{Conclusions}

So far, there is no evidence that brief PD in this study had any serious or significant growth and development consequence to the child. Longer-term follow up on a larger sample size may be needed.

\section{Additional files}

Additional file 1: Definition of training by parents.

Additional file 2: Definition of child's capability.

\section{Abbreviations}

PD: Perioperative desaturation; PDD: Pervasive developmental disorders; PRE: Perioperative respiratory events; GA: General anesthesia; ASA: American Society of Anesthesiologists; PACU: Post-anesthetic care unit; IQ: Intelligence quotient; ASWP: Age-specific weight percentile; ASHP: Age-specific height percentile; $\mathrm{SpO}_{2}$ : Oxygen saturation by pulse oximetry.

\section{Competing interests}

The authors have no conflicts of interest to declare. 


\section{Authors' contributions}

This study was conceived by MO. Anesthetic database were collected by BS, BS and KN. The manuscript was drafted by MO. AFG, VC, TC and JW read and corrected the manuscript. All authors also read and approved the final manuscript.

\section{Acknowledgements}

We would like to thank the Faculty of Medicine, Prince of Songkla University, for co-funding this research project. This study forms part of the dissertation of the first author to fulfil the requirement for PhD in Epidemiology at Prince of Songkla University. It is also financially supported by the Thailand Research Fund through a Royal Golden Jubilee PhD program award to Assistant Professor Maliwan Oofuvong and Dr Alan F. Geater.

\section{Author details}

'Department of Anesthesiology, Faculty of Medicine, Prince of Songkla University, Songkhla 90112, Thailand. ${ }^{2}$ Epidemiology Unit, Faculty of Medicine, Prince of Songkla University, Songkhla 90112, Thailand. ${ }^{3}$ Division of Child Development, Department of Pediatrics, Faculty of Medicine, Prince of Songkla University, Songkhla 90112, Thailand

\section{Received: 5 March 2014 Accepted: 21 March 2014}

\section{Published: 29 March 2014}

\section{References}

Baburamani AA, Ek CJ, Walker DW, Castillo-Melendez M (2012) Vulnerability of the developing brain to hypoxic-ischemic damage: contribution of the cerebral vasculature to injury and repair? Front Physiol 3:424, 10.3389/fphys. 2012.00424

Ballweg JA, Wernovsky G, Gaynor JW (2007) Neurodevelopmental outcomes following congenital heart surgery. Pediatr Cardiol 28:126-133

Becker KA (2003) History of the Stanford-Binet Intelligence Scales: Content and Psychometrics. Riverside Publishing, Illinois

Bocca-Tjeertes IF, Kerstjens JM, Reijneveld SA, de Winter AF, Bos AF (2011) Weight, height and predictors of weight, height restraint in moderately preterm children aged 0 to 4 years. Pediatrics 128:e1187-e1194

Boscolo A, Milanovic D, Starr JA, Sanchez V, Oklopcic A, Moy L, Ori CC, Erisir A Jevtovic-Todorovic V (2013) Early exposure to general anesthesia disturbs mitochondrial fission and fusion in the developing rat brain. Anesthesiology 118:1086-1097

Freberg ME, Vandiver BJ, Watkins MW, Canivez GL (2008) Significant factor score variability and the validity of the WISC-III Full Scale IQ in predicting later academic achievement. Appl Neuropsychol 15:131-139

Gardener H, Spiegelman D, Buka SL (2011) Perinatal and neonatal risk factors for autism: a comprehensive meta-analysis. Pediatrics 128:344-355, 10.1542/ peds.2010-1036

Guerra GG, Robertson CM, Alton GY, Joffe AR, Cave DA, Dinu IA, Creighton DE, Ross DB, Rebeyka IM, Western Canadian Complex Pediatric Therapies Follow-up Group (2011) Neurodevelopmental outcome following exposure to sedative and analgesic drugs for complex cardiac surgery in infancy. Paediatr Anaesth 21:932-941

Hansen G, Joffe AR, Nettel-Aguirre A, Robertson CM, Biggs WS, Ross DB, Rebeyka IM (2011) Two-year survival and neurodevelopmental outcomes after cardiopulmonary resuscitation in neonatal patients after complex cardiac surgery. Resuscitation 82:313-318

Hill CM, Hogan AM, Onugha N, Harrison D, Cooper S, McGrigor VJ, Datta A, Kirkham FJ (2006) Increased cerebral blood flow velocity in children with mild sleep-disordered breathing: a possible association with abnormal neuropsychological function. Pediatrics 118:e1100-e1108

Hovels-Gurich HH, Bauer SB, Schnitker R, Willmes-von HK, Messmer BJ, Seghaye MC, Huber W (2008) Long-term outcome of speech and language in children after corrective surgery for cyanotic or acyanotic cardiac defects in infancy. Eur J Paediatr Neurol 12:378-386

Hovels-Gurich HH, Konrad K, Skorzenski D, Nacken C, Minkenberg R, Messmer BJ, Seghaye MC (2006) Long-term neurodevelopmental outcome and exercise capacity after corrective surgery for tetralogy of Fallot or ventricular septal defect in infancy. Ann Thorac Surg 81:958-966

Hövels-Gürich HH, Seghaye MC, Sigler M, Kotlarek F, Bartl A, Neuser J, Minkenberg R, Messmer BJ, von Bernuth G (2001) Neurodevelopmental outcome related to cerebral risk factors in children after neonatal arterial switch operation. Ann Thorac Surg 71:881-888
Kayaalp L, Bozkurt P, Odabasi G, Dogangun B, Cavusoglu P, Bolat N, Bakan M (2006) Psychological effects of repeated general anesthesia in children. Paediatr Anaesth 16:822-827

Martin RJ, Wang K, Koroglu O, Di FJ, Kc P (2011) Intermittent hypoxic episodes in preterm infants: do they matter? Neonatology 100:303-310

Moilanen KL, Shaw DS, Dishion TJ, Gardner F, Wilson M (2009) Predictors of Longitudinal Weight, height in Inhibitory Control in Early Childhood. Soc Dev 19:326-347

Raven JC (1938) Raven's standard progressive matrices. HK Lewis, London

Sananes R, Manlhiot C, Kelly E, Hornberger LK, Williams WG, MacGregor D, Buncic R, McCrindle BW (2012) Neurodevelopmental outcomes after open heart operations before 3 months of age. Ann Thorac Surg 93:1577-1583

Sandjaja PBK, Rojroonwasinkul N, Le Nyugen BK, Budiman B, Ng LO, Soonthorndhada K, Xuyen HT, Deurenberg P, Parikh P, SEANUTS Study Group (2013) Relationship between anthropometric indicators and cognitive performance in Southeast Asian school-agedchildren. Br J Nutr 110(Suppl 3): S57-S64

Sun L (2010) Early childhood general anaesthesia exposure and neurocognitive development. Br J Anaesth 105(Suppl 1):i61-i68, 10.1093/bja/aeq302

Sungthong R, Mo-suwan L, Chongsuvivatwong V, Geater AF (2004) Once-weekly and 5-days a week iron supplementation differentially affect cognitive function but not school performance in Thai children. J Nutr 134:2349-2354

Tabbutt S, Gaynor JW, Newburger JW (2012) Neurodevelopmental outcomes after congenital heart surgery and strategies for improvement. Curr Opin Cardiol 27:82-91

Vanderveen JA, Bassler D, Robertson CM, Kirpalani H (2009) Early interventions involving parents to improve neurodevelopmental outcomes of premature infants: a meta-analysis. J Perinatol 29:343-351

Watkins MW (1996) Diagnostic utility of the WISC-III developmental index as a predictor of learning disabilities. J Learn Disabil 29:305-312

Wise-Faberowski L, Loepke A (2011) Anesthesia during surgical repair for congenital heart disease and the developing brain: neurotoxic or neuroprotective? Paediatr Anaesth 21:554-559

Xue FS, Luo LK, Tong SY, Liao X, Deng XM, An G (1996) Study of the safe threshold of apneic period in children during anesthesia induction. J Clin Anesth 8:568-574

\section{doi:10.1186/2193-1801-3-164}

Cite this article as: Oofuvong et al:: Comparison of intelligence, weight and height in children after general anesthesia with and without perioperative desaturation in non-cardiac surgery: a historical and concurrent follow-up study. SpringerPlus 2014 3:164.

\section{Submit your manuscript to a SpringerOpen ${ }^{\odot}$ journal and benefit from:}

- Convenient online submission

- Rigorous peer review

- Immediate publication on acceptance

- Open access: articles freely available online

- High visibility within the field

- Retaining the copyright to your article

Submit your next manuscript at $>$ springeropen.com 